\title{
Análise espacial dos acidentes de trânsito com vítimas fatais: comparação entre o local de residência e de ocorrência do acidente no Rio de Janeiro
}

\author{
Vanessa dos Reis de Souza* \\ Suzana Cavenaghi** \\ José Eustáquio Diniz Alves*** \\ Mônica de Avelar Figueiredo Mafra Magalhães ${ }^{\star \star * *}$
}

\begin{abstract}
Este trabalho tem por objetivo comparar a distribuição espacial dos óbitos por acidentes de trânsito na cidade do Rio de Janeiro, em 2003, a partir de três tipos de endereço: residência da vítima; local de ocorrência do acidente; e local de ocorrência do óbito, em nível de setor censitário. Utilizou-se o Estimador de Kernel para verificar se existe ou não diferença nos padrões de áreas de risco determinados a partir dos registros destes endereços. Concluiu-se que há diferença nos padrões espaciais, em todos os tipos de endereço utilizados. Dessa forma, mostra-se como o mapeamento dos acidentes, identificando o local de ocorrência deste, é essencial, pois fornece subsídios às ações de políticas públicas para redução e prevenção dos acidentes. Para tanto, são necessárias algumas medidas administrativas que permitam a sistematização e o registro da informação adequada.
\end{abstract}

Palavras-chave: Acidentes de trânsito. Mortalidade. Análise espacial. Rio de Janeiro.

\section{Introdução}

O município do Rio de Janeiro apresentou, em 2003, uma razão de mortalidade por acidentes de transporte de aproximadamente 15,6 por 100 mil habitantes, superior à verificada em muitos países no mesmo ano, tais como Canadá $(9,8$ por $100 \mathrm{mil})$, França $(9,9)$, Alemanha $(8,5)$, Itália $(11,0)$ e Japão $(7,0)$ (IRTAD, 2003). A cidade tornouse assim alvo de diversas preocupações de políticas públicas, tanto da perspectiva da saúde como da violência do trânsito.
A geração de informações sobre os acidentes de trânsito, para estudos de segurança viária, é fundamental para subsidiar as tomadas de decisões e melhorias na segurança pública. Adicionalmente, esses dados podem ser utilizados por outros setores, tais como educação e fiscalização do transporte, servindo de alicerce para diminuição do risco de acidentes (CARDOSO, 2002).

Apesar da melhoria na qualidade dos registros do Sistema de Informações de Mortalidade (SIM), para sua identificação e caracterização, ainda existem muitos proble-

\footnotetext{
* Doutoranda em Saúde Coletiva - Instituto de Medicina Social, Universidade do Estado do Rio de Janeiro, mestre em Estudos Populacionais e Pesquisas Sociais.

** Doutora em Demografia, professora e pesquisadora da Escola Nacional de Ciências Estatísticas, Instituto Brasileiro de Geografia e Estatística - IBGE.

${ }_{* \star \star}$ Doutor em Demografia, professor e pesquisador da Escola Nacional de Ciências Estatísticas, Instituto Brasileiro de Geografia e Estatística - IBGE.

**** Mestre em Engenharia de Sistemas, coordenadora do Laboratório de Geoprocessamento do Instituto de Comunicação e Informação Científica e Tecnológicas, Fundação Oswaldo Cruz.
} 
mas conceituais e metodológicos (MELLO JORGE et al., 2007) que dificultam o amplo conhecimento do perfil de acidentes, principalmente a identificação de áreas de risco. Os registros de mortalidade do SIM disponibilizam os dados por locais de residência e de ocorrência do óbito, o que possibilita análise tanto do aspecto de localização das vítimas e suas condições socioeconômicas quanto da identificação de áreas de risco. Porém, no caso dos acidentes, os locais de ocorrência do óbito registrados correspondem, em grande parte, aos hospitais onde as vítimas faleceram e não ao local de ocorrência dos eventos (que pode ser uma localidade muito distante do hospital). Análises anteriores mostram como as áreas de risco mudam ao se considerarem os locais de ocorrência do óbito e o local de residência da vítima, como, por exemplo, em estudo para a cidade do Rio de Janeiro (SOUZA et al., 2006; SOUZA, 2007) e para o município de São Paulo (MAIA; AIDAR, 2008). O registro correto do local de ocorrência do acidente caracteriza exatamente as áreas de risco que devem ser objeto de planejamento e estudo.

O objetivo desse trabalho é comparar as áreas de risco - por meio do georreferenciamento dos endereços por local de residência da vítima, local do óbito e local de ocorrência dos acidentes em nível de setor censitário -, mostrando a importância da informação do local de ocorrência do acidente para uma melhor identificação das áreas de risco e da população mais exposta. Partese da premissa de que conhecer o local de ocorrência dos acidentes permite ações preventivas que visem diminuir o número de acidentes de trânsito com vítimas fatais.

\section{Antecedentes}

Apesar da melhoria na cobertura do número de casos e dos esforços para melhorar a qualidade do preenchimento das declarações de óbitos, ainda existem problemas estruturais para análise das causas de morte por acidentes de trânsito. A primeira questão refere-se à qualidade da informação sobre o endereço na declaração de óbitos, o qual, em muitos casos, é inexistente e, mesmo quando está registrado, a localização correta da ocorrência ou residência do óbito fica comprometida devido à inexistência de um cadastro de logradouros completo e atualizado.

Uma segunda questão que deve ser considerada na análise destas declarações de óbito é o uso do registro dos endereços de ocorrência do óbito e não da localidade da ocorrência dos acidentes. Estes dados somente coincidem quando a morte ocorre no local do acidente, mas, se a vítima é transportada para um hospital e falece após o acidente, o registro de ocorrência do óbito e o do evento são diferentes.

O trabalho de georreferenciamento dos dados de óbitos, a partir dos endereços declarados - por local de residência da vítima, local de ocorrência do acidente e local de ocorrência do óbito - é de fundamental importância para avanços nas análises sobre áreas de risco, mas ainda é fastidioso, moroso e incompleto, mesmo em níveis agregados como setores censitários e não o desejado, que seria por endereço de porta ou segmento de ruas. Como afirmam Reinhold e Goldner (2005), o uso dos Sistemas de Informações Geográficas (SIG) tem sido importante no estudo de acidentes em geral. A análise espacial dos óbitos torna possível a tomada de decisões nas soluções para problemas no trânsito. O geoprocessamento tem se tornado mais usual pela ampliação do acesso a dados da área da saúde e também pela disponibilidade dos SIGs (SANTOS; NORONHA, 2001). No entanto, os sistemas de registro de dados ainda não estão preparados para plena utilização nesse ambiente computacional, o que dificulta análises rápidas das áreas e situações de risco que são essenciais para o bom planejamento e gestão da saúde. Como ressalta Skaba et al. (2004, p.1.753), "o georreferenciamento dos eventos de saúde é importante na análise e avaliação de riscos à saúde coletiva, particularmente as relacionadas com o meio ambiente e com o perfil socioeconômico da população".

Vale destacar que é fundamental para se ter um bom georreferenciamento de eventos, seja da área de saúde seja de qualquer outra, a qualidade dos dados de endereços (SANTOS et al., 1996). Sabe-se que os registros de endereços no Brasil apresentam 
problemas graves, principalmente nas áreas mais pobres e rurais, justamente as mais carentes de implementação de programas e políticas públicas voltadas para melhorar as condições de vida da população (BARCELLOS et al., 2008).

É necessário fazer um esforço conjunto unindo instituições detentoras de dados de endereços para criar um bom cadastro de logradouros. Uma solução técnica para o georreferenciamento de dados nessas áreas mais difíceis é o uso de GPS (Global Position System), mas nesse estudo não foi utilizado. A seguir, detalham-se a metodologia empregada e as escolhas que foram necessárias para viabilizar o estudo.

\section{Metodologia}

\section{Dados}

O registro de eventos como acidente de trânsito é feito por vários sistemas administrativos e de gerenciamento. A fonte de dados mais utilizada na área da saúde e mais bem sistematizada é aquela gerenciada pela Secretaria de Vigilância da Saúde/MS, o SIM, que é a fonte de dados selecionada para este estudo. Neste, está disponível a décima versão da Classificação Internacional de Doenças (CID-10), que possui um capítulo destinado às causas externas (capítulo XX), com um subgrupo sobre acidentes de transporte. Neste capítulo, foram separados os tipos de acidentes: de trânsito ou não. Os óbitos classificados como acidentes de trânsito, para 2003, desagregados em quatro categorias - pedestre (atropelamento), acidente com e sem colisão e acidente de trânsito não especificado - foram selecionados. Adicionalmente, restringiram-se os óbitos àqueles acidentes ocorridos no município do Rio de Janeiro e cujas vítimas residiam e faleceram neste mesmo município, totalizando 740 mortes.

Um trabalho grande de busca dos endereços de local de ocorrência dos acidentes foi realizado junto à Polícia Civil, com base nas informações contidas nos registros de ocorrência. Para o exercício de georreferenciamento dos endereços relacionados aos óbitos, detalhado mais adiante, foi utilizada a malha digital para os setores censitários (IBGE, 2000).

Indicador de mortalidade por acidentes de trânsito

No cálculo das taxas de mortalidade por acidentes de trânsito, confronta-se com uma questão metodológica praticamente sem solução a contento, que é determinar a população exposta ao risco de mortes, ou seja, o denominador do indicador (CARVALHO; CRUZ, 1998). A população exposta ao risco de acidentes de trânsito é de difícil mensuração, pois trata-se de uma população flutuante. Algumas propostas para definir a taxa de mortalidade por acidentes de trânsito, como utilizar o número de veículos por habitantes, foram analisadas (KILSZTAJN et al., 2000). No entanto, em um nível desagregado como o setor censitário, seria muito difícil a mensuração do tamanho da frota que trafega nos diversos setores. Em Barros et al. (2003), foram calculadas taxas por 100 mil habitantes e por 10 mil veículos registrados, entretanto, fala-se sobre as possíveis distorções que essas taxas podem acarretar. Por exemplo, o aumento da frota de veículos não acompanha o crescimento populacional, como no caso da cidade de São Paulo, que teve uma queda de $46 \%$ da taxa de acidentes por veículo, entre 1990 e 1997, porém, segundo a população residente, essa redução foi de $27 \%$, no mesmo período. Isso pode ser explicado pelo aumento de $40 \%$ na frota de veículos e de apenas $5 \%$ de crescimento populacional.

Adiciona-se a esta questão o fato de que a população sujeita aos acidentes não é necessariamente aquela residente na área. Ou seja, tanto a frota como a população são flutuantes em uma área geográfica delimitada. A utilização de diferentes denominadores está muito relacionada com o enfoque da análise em questão. Como um exemplo bastante amplo, no caso de se buscar um enfoque mais vinculado à saúde pública, a população residente poderia ser utilizada como denominador da taxa, no entanto, se o foco da análise reside em medir a violência no trânsito, deveria levar em consideração o tamanho da frota. 
Ainda com relação aos dados populacionais em nível de setor censitário, agrega-se outra questão importante a ser considerada, que é a inexistência de informações atualizadas sobre número de habitantes nestes setores. Assim, os dados da população para os diferentes níveis de agregação geográfica teriam que ser estimados por algum método matemático ou demográfico. Nesse trabalho, optou-se por utilizar o valor absoluto dos acidentes por setor censitário, ou seja, não se utilizaram taxas, mas sim a incidência total.

\section{Georreferenciamento dos dados}

Os dados foram georreferenciados nos setores censitários por meio dos endereços do local de ocorrência do acidente, local de ocorrência do óbito e local de residência da vítima. O setor censitário foi escolhido como unidade de georreferenciamento por ser o nível mais desagregado que possui dados populacionais coletados periodicamente (XIMENES et al., 1999). A informação pontual da ocorrência do acidente seria ainda mais adequada, mas, como mostrado por Nery e Monteiro (2006), o setor censitário capta com boa precisão os padrões de ocorrência de eventos ligados às causas externas de morte. Além disso, nos municípios mais povoados, é necessária a utilização de pequenas áreas a fim de depurar a análise (SKABA et al., 2004; CARVALHO; SANTOS, 2005). Os endereços foram georreferenciados em um programa desenvolvido no Laboratório de Geoprocessamento do Instituto de Comunicação e Informação Científica e Tecnológicas da Fundação Oswaldo Cruz.

Este programa de georreferenciamento consiste basicamente na padronização e adequação do campo endereço do banco a ser trabalhado e sua comparação com o cadastro de logradouros por setor censitário do Instituto Brasileiro de Geografia e Estatística, que é denominado de banco de dados de referência.

A rotina de georreferenciamento é realizada por meio do relacionamento (linkage) de endereços contidos no banco de dados original, o que se quer georreferenciar, com os endereços existentes no banco de dados de referência. Visando minimizar a perda de registros, os endereços não localizados pelo programa foram procurados manualmente através de pesquisa em listas telefônicas e guias de ruas, cujo objetivo é encontrar o endereço mais perto do real. Por exemplo: o endereço que consta na base de dados é avenida $A$, número 48, mas no cadastro de logradouros esse endereço não existe; então, na busca manual, encontra-se avenida $A$, número 46 . Como os dois endereços pertencem ao mesmo setor censitário, é aceito o georreferenciamento do segundo endereço encontrado.

\section{Método}

\section{Áreas de risco}

Para obter o mapa das áreas de risco do município do Rio de Janeiro, optou-se pelo método de suavização de Kernel, que calcula a intensidade pontual do evento. "Esta função realiza uma contagem de todos os pontos dentro de uma região de influência, ponderando-os pela distância de cada um à localização de interesse" (CARVALHO et al., 2004).

A função é dada por:

$$
\hat{\lambda}_{\tau}(s)=\sum_{i=1}^{n} \frac{3}{\pi \tau^{2}}\left(1-\frac{h_{i}^{2}}{\tau^{2}}\right)^{2}
$$

Onde:

$\tau$ é o raio de influência;

$h$ é a distância entre o ponto s e o ponto observado $s_{j}$.

Assim, a região de influência será um círculo de raio $\tau$ com centro em $s$, sendo que o raio de influência "define a vizinhança do ponto a ser interpolado e controla o 'alisamento' da superfície gerada" e $\hat{\lambda}_{\tau}(s)$ é "uma função de estimação com propriedades de suavização do fenômeno" (CARVALHO et al., 2004).

A região de influência determina a suavização da superfície gerada, que é definida a partir do fenômeno em estudo e pode variar de acordo com a divisão geográfica utilizada. Porém, quanto maior o raio utilizado, maior será a suavização da superfície. Assim, o resultado pode sugerir uma homogeneidade na região que, de fato, pode não existir. Em contrapartida, quanto menor 
for o tamanho do raio de influência, mais descontínua ficará a região (CARVALHO et al., 2004), gerando picos concentrados em $s$ (CARNEIRO; SANTOS, 2003). Dessa forma, é possível verificar se os endereços do local de residência, local de ocorrência do acidente e local do óbito diferem espacialmente na cidade do Rio de Janeiro.

Para o cálculo do raio, utilizou-se o algoritmo que busca soluções ótimas e com raios variáveis para uma mesma estimação, que é definida segundo a densidade dos pontos; ou seja, nas áreas onde os pontos são mais disseminados, o algoritmo, para abranger um número suficiente de pontos, utiliza um raio maior. Ainda foram utilizados os dados do centróide do setor censitário como pontos de localização dos eventos.

\section{Resultados e discussão}

Apesar de todo o trabalho desenvolvido neste estudo, não foi possível obter todos os endereços de ocorrência do acidente - em 12\% (89) dos óbitos não foram encontradas informações sobre o local de ocorrência. Tendo em vista que muitos corpos são encontrados em valas ou outras situações adversas, em uma cidade violenta como o Rio de Janeiro, acredita-se que esta perda é aceitável. No entanto, já se menciona aqui a necessidade de um melhor registro deste tipo de informação na declaração de óbito.

No que tange o georreferenciamento dos endereços, os resultados positivos foram: cerca de $85 \%$ de endereços de residência; $3 \%$ dos endereços de ocorrência do evento; e 95\% dos endereços de ocorrência do óbito.

A partir da análise do Gráfico 1, é possível verificar se o georreferenciamento causou distorção nos dados nas áreas de planejamento, através da comparação dos percentuais dos eventos georreferenciados por bairro e por setor censitário. A escolha destas duas unidades espaciais deveu-se ao fato de a unidade geográfica bairro possuir o maior número de endereços georreferenciados, já que é uma área maior e no processo de georreferecenciamento não requer tanta precisão quanto os setores censitários, que, para serem localizados, é necessário conhecer o endereço completo do evento.

Desse modo, pode-se observar que as distribuições dos tipos de endereço apresentam-se relativamente iguais quando são agregadas para área de planejamento, que é a maior unidade geográfica da cidade do Rio de Janeiro. Assim, vê-se que o georreferenciamento não causou tendência enviesada na análise espacial, seja qual for o nível geográfico utilizado.

O Mapa 1 apresentam os resultados da função Kernel para os óbitos por local de residência da vítima, de ocorrência do acidente e de ocorrência do óbito, segundo setores censitários. Pode-se observar que as áreas de risco diferem muito entre si quando são considerados estes três diferentes locais de "acontecimento" do evento. O mapa por local de ocorrência do óbito serve, principalmente, para identificar onde as vítimas foram atendidas e vieram a falecer, pois, na maioria dos casos, esses locais correspondem a unidades hospitalares. Estas ficam concentradas em algumas regiões, que possuem as emergências da cidade do Rio de Janeiro. A área com maior intensidade é o centro da cidade - isso pode ser explicado pelo fato de essa região possuir grande ocorrência de acidentes, além de ter a maior emergência da cidade, o Hospital Municipal Souza Aguiar. O mapa por local de residência, também muito utilizado e conhecido na literatura, mostra áreas importantes de alto risco de morte por acidente de trânsito, mas as áreas são mais espalhadas do que aquelas mostradas no mapa de risco por local de ocorrência do acidente. Sabe-se que grande parte dos acidentes ocorre perto do local de residência e está é, em geral, a motivação para se utilizar tal informação na análise de risco. No entanto, em uma área urbana e densa como o Rio de Janeiro, faz muita diferença, para o planejamento e a tomada de medidas preventivas para redução de acidentes, considerar as áreas de risco aquelas referentes ao local de residência ou aquelas correspondentes ao local do acidente. $\mathrm{Ou}$ seja, conhecer o local do acidente delimita muito melhor a área de risco, como já era previsto, além de dar melhor informação sobre a intensidade do evento. 


\section{GRÁFICO 1}

Distribuição dos endereços de óbitos por acidente de transito georreferenciados por Área de Planejamento, segundo bairro e setor censitário Município do Rio de Janeiro - 2003
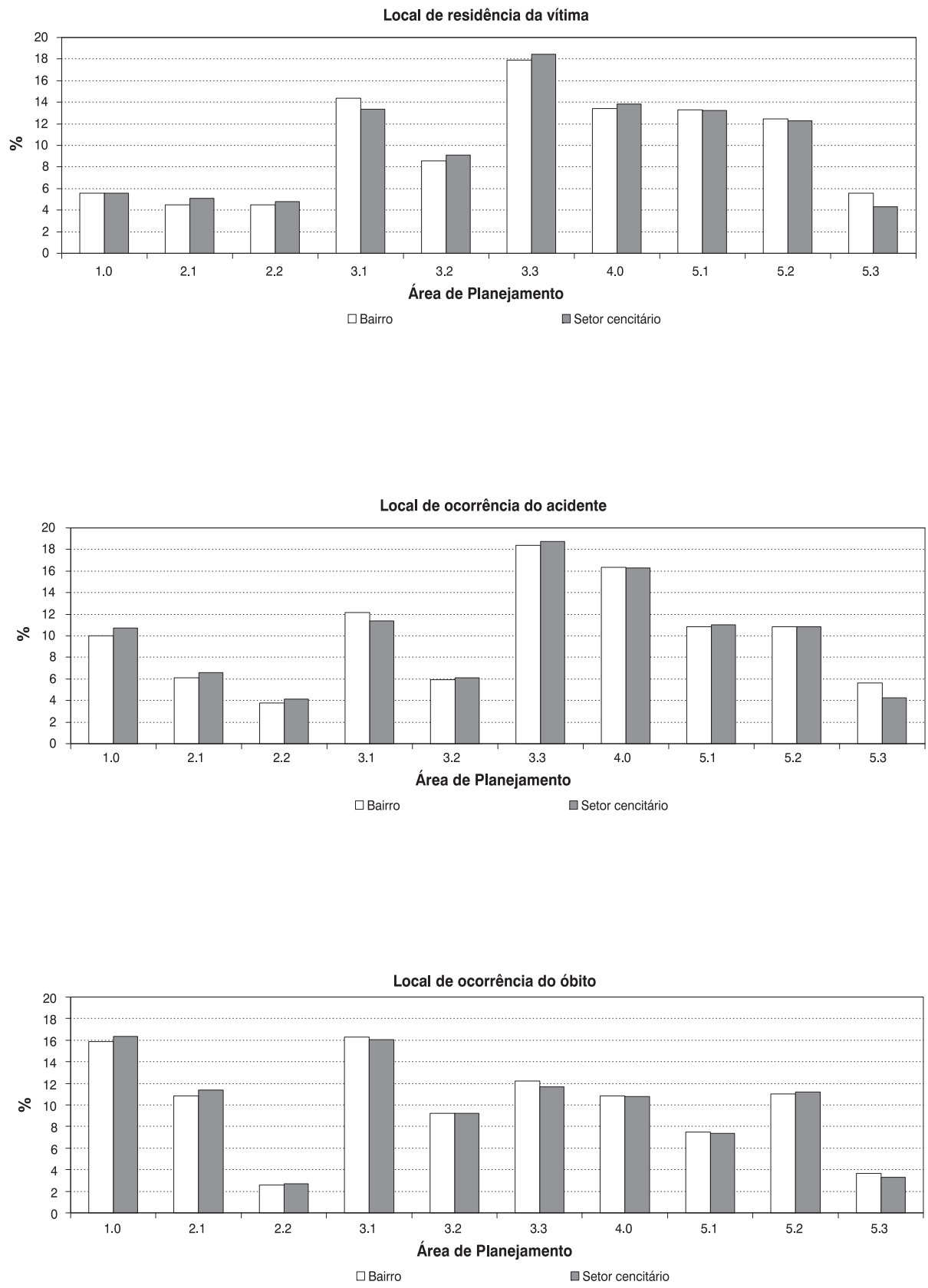

Fonte: Sistema de Informações de Mortalidade, 2003. 
MAPA 1

Intensidade pontual da mortalidade por acidentes de trânsito, por local de residência, de ocorrência do acidente e de ocorrência do óbito, segundo setor censitário Município do Rio de Janeiro - 2003

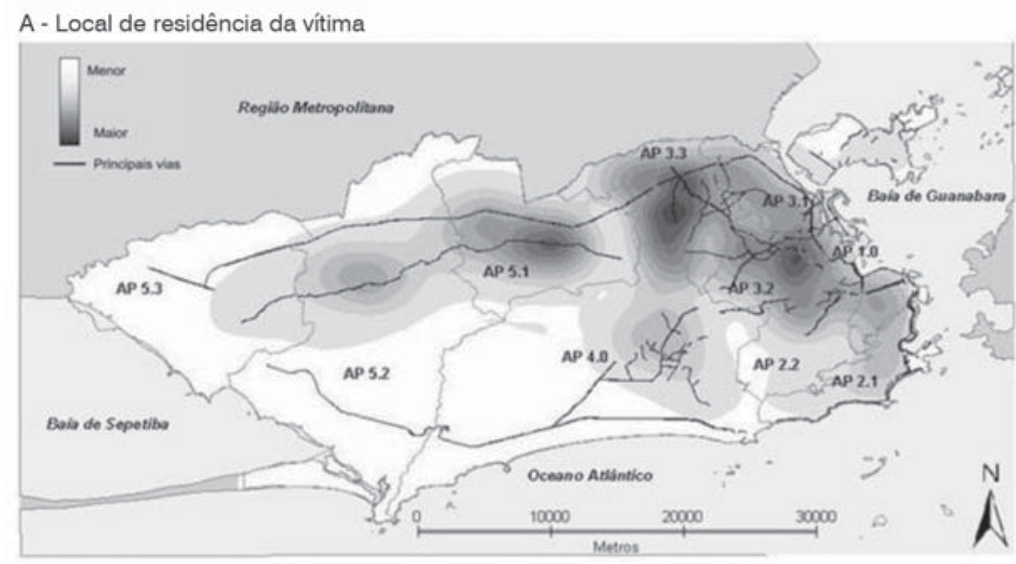

B- Local de ocorrência do acidente

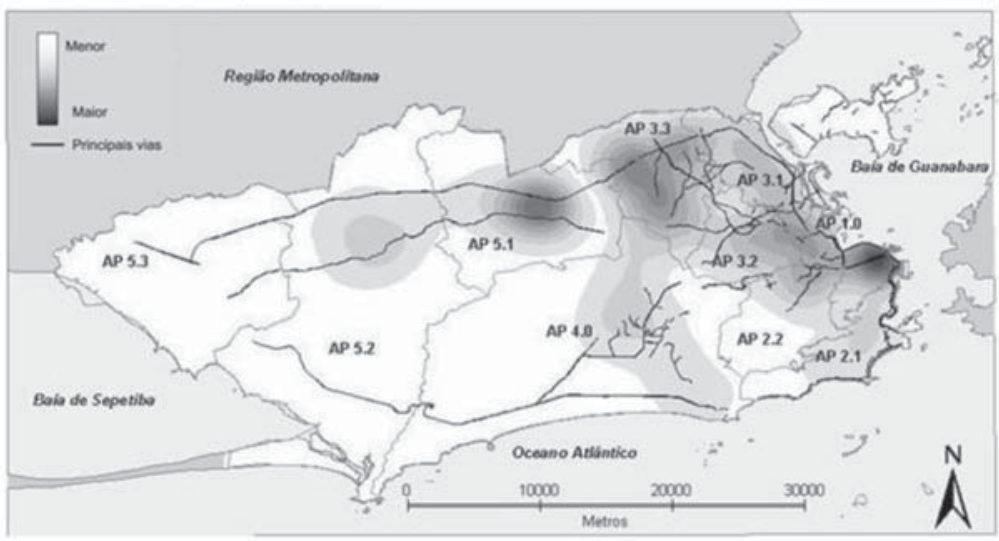

C - Local de ocorrência do óbito

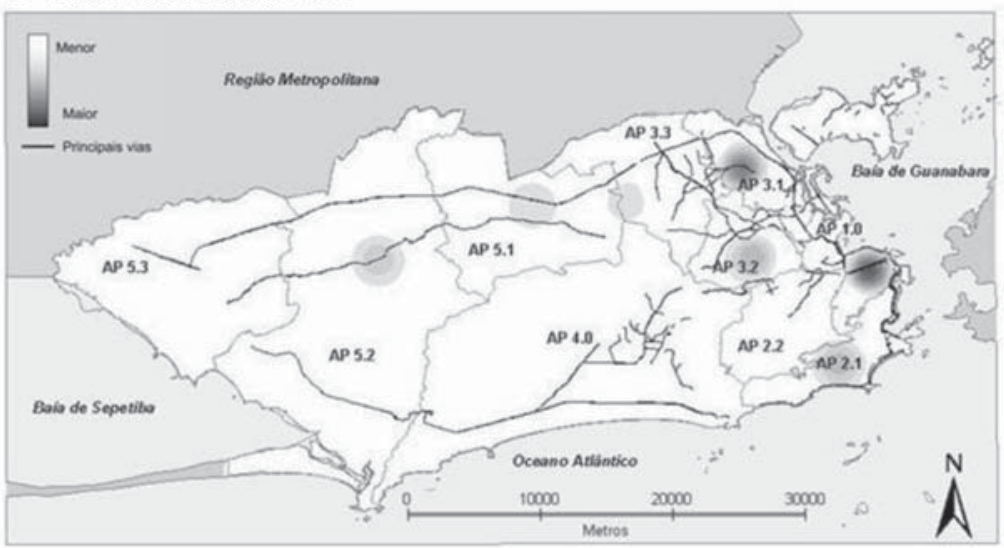

Fonte: Sistema de Informações de Mortalidade, 2003. 
Estimador de intensidade por tipo de acidente de trânsito

Para aplicação de medidas preventivas, é importante conhecer o tipo de acidente de trânsito e onde cada um ocorre. Estimam-se aqui somente os mapas de risco por tipo de acidente segundo o local de ocorrência e o local de residência das vítimas, já que se sabe que o local de ocorrência do óbito é pouco informativo. O mapa de Kernel foi novamente empregado, classificando-se as ocorrências do local do acidente e do local de residência, segundo dois tipos de acidentes: atropelamento (492 óbitos) e "outros" (248 óbitos). Deve-se detacar que as colisões representam $75 \%$ (187 óbitos) do grupo classificado como "outros".
O Mapa 2 mostra os dados de óbitos por atropelamento e aqueles classificados como "outros óbitos", segundo local de ocorrência do acidente. Nota-se uma concentração dos atropelamentos no centro da cidade, com aproximadamente $7 \%$ do total de atropelados, sendo este o bairro com o maior número de vítimas por esta causa de morte. Esse fato pode ser explicado pelo grande fluxo de pedestres na região. Já os outros tipos de acidentes se concentraram numa região por onde passa uma das principais vias da cidade, a Avenida Brasil.

As áreas de risco por tipo de acidente segundo local de residência das vítimas são mostradas no Mapa 3. Comparando-se este mapa com aquele por local de ocorrência (Mapa 2), notam-se novamente os distintos

A - Atropelamentos
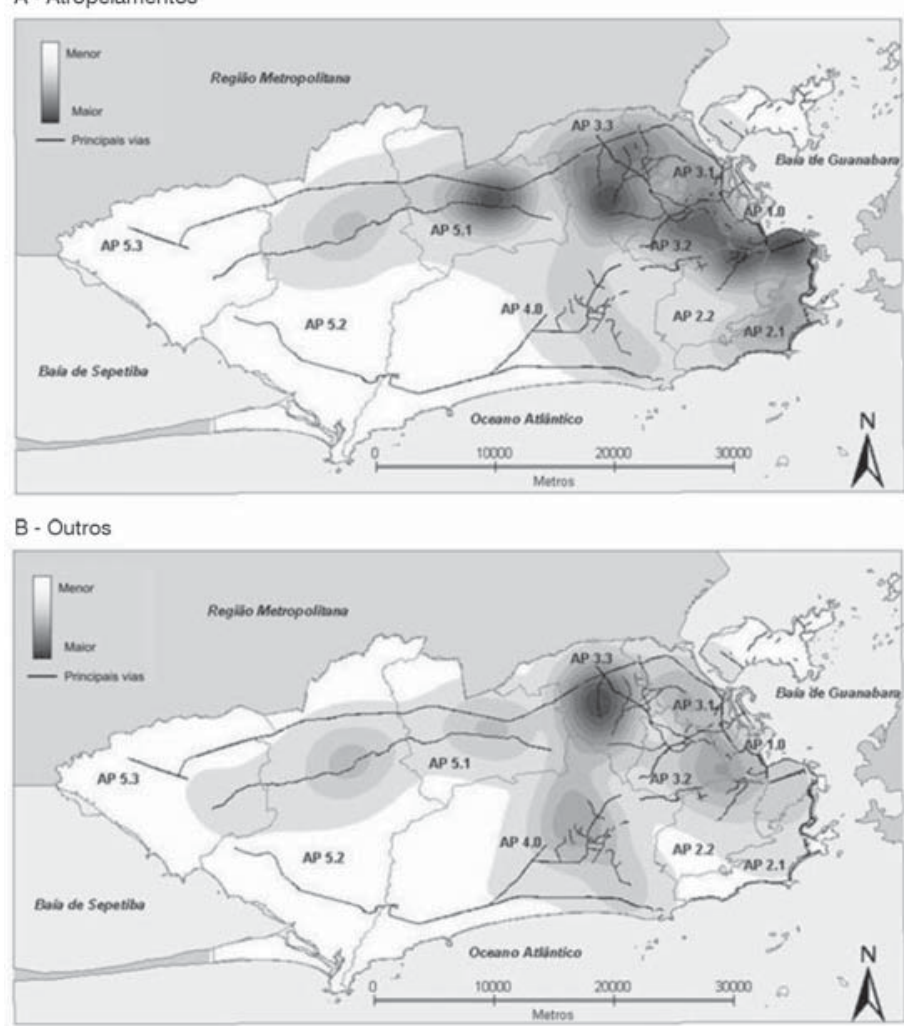

Fonte: Sistema de Informações de Mortalidade, 2003. 
MAPA 3

Intensidade pontual da mortalidade por acidentes de trânsito, por local de residência da vítima e tipo de acidente, segundo setor censitário

Município do Rio de Janeiro - 2003
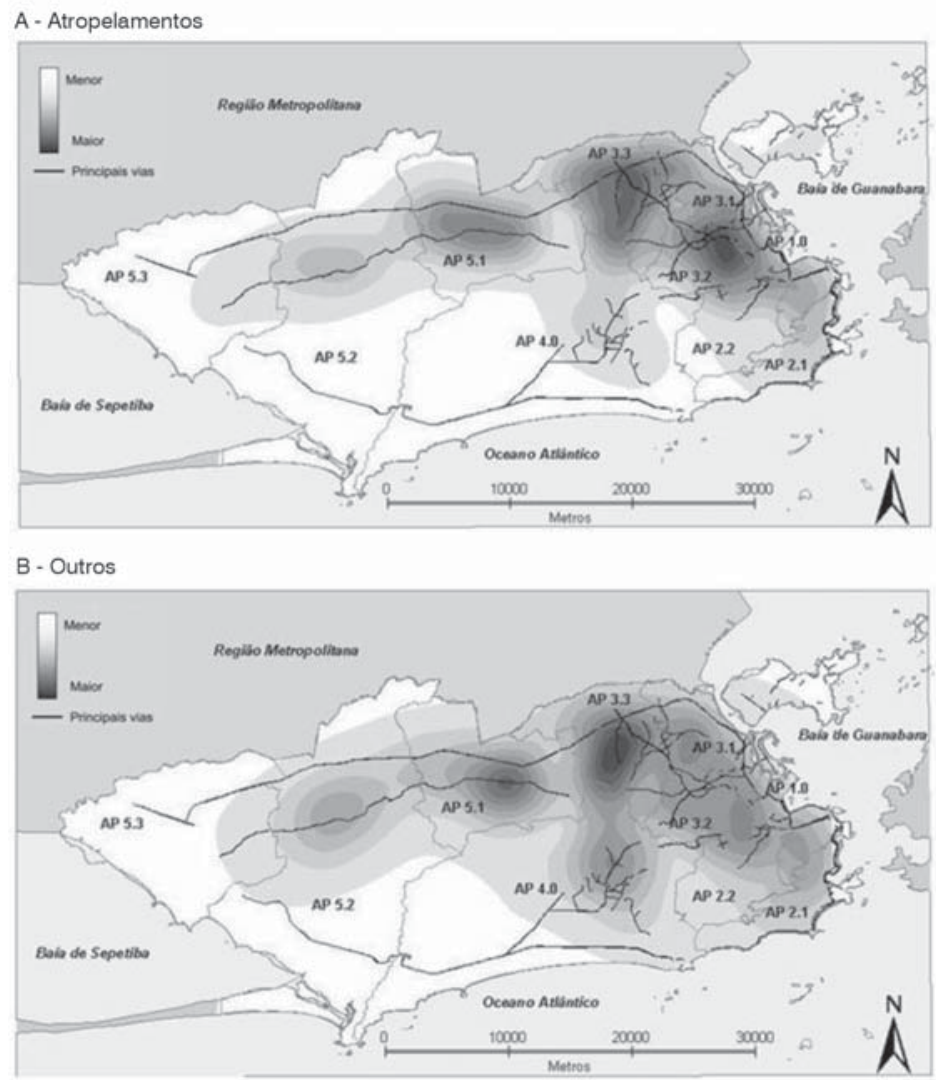

Fonte: Sistema de Informações de Mortalidade, 2003.

padrões espaciais, diferenciando as áreas de risco que estes dois tipos de informação brindam. Os atropelamentos acontecem mais no centro do Rio de Janeiro, mas a população vítima de atropelamentos mora mais ao norte da cidade e parte da zona oeste. Já os outros tipos de acidentes, que na maioria são colisões, ocorrem mais na zona norte e a população vítima desse acidentes mora também na zona norte e parte da zona oeste.

\section{Conclusão}

A análise espacial dos acidentes de trânsito no município do Rio de Janeiro, para 2003, mostrou que existem diferenças expressivas entre local de residência da vítima, local do óbito e local onde ocorreu $\mathrm{o}$ acidente. A análise de Kernel segundo o tipo de acidente mostrou que as colisões apresentam um padrão espacial seguindo as principais vias da cidade, enquanto os atropelamentos são mais freqüentes no centro da cidade, sugerindo que há uma relação entre esta ocorrência e o fluxo de pessoas no local. Os casos por local de ocorrência do óbito estão mais concentrados no Hospital Municipal Souza Aguiar, havendo, para isso, duas possíveis causas: é um hospital localizado no centro do Rio de Janeiro e próximo a uma parcela considerável das ocorrências; e trata-se da maior unidade de emergência da cidade. 
Este estudo também mostra que, quando se trabalha com os dois endereços (residência e ocorrência do óbito), obtémse um "retrato" diferente da cidade para cada local. Por isso, quando se pretende evidenciar as áreas de maior incidência de acidentes de trânsito, deve-se trabalhar com os endereços de ocorrência do evento. Porém, se o objetivo for mostrar onde se localiza a população mais vitimada pelos acidentes, deve-se então utilizar os endereços de residência.

Estes resultados apontam para a importância da continuidade deste tipo de análise. Para tanto, são necessárias a qualificação dos dados e uma análise periódica destes, o que permitiria ações preventivas locais e assim, provavelmente, a redução da mortalidade por acidente de trânsito. Dessa forma, esforços no sentido de melhorar a produção dos dados, buscando desenvolver e aprimorar um cadastro de logradouros atualizado são promissores. É essencial sistematizar e padronizar a informação já existente, de forma a ampliar o preenchimento das variáveis que constam na declaração de óbito, como, por exemplo, o local de ocorrência do evento, que possui um item separado. Caso o óbito não-natural aconteça em via pública, este item deve ser preenchido, mas não é o que acontece na atualidade, pois esta informação é praticamente inexistente nas DOs preenchidas.

Assim, é essencial também investir em ações para melhorar a qualidade do preenchimento, com capacitação de pessoal. Acredita-se que uma melhor cooperação entre os órgãos da Secretaria Municipal de Saúde, Secretaria de Segurança Pública e departamentos produtores de dados da Polícia Civil possibilitaria a formação de um banco de dados mais completo, que pode-

\section{Referências bibliográficas}

BARCELLOS, C.; RAMALHO, W. M.; GRACIE, R. et al. Georreferenciamento de dados de saúde na escala submunicipal: algumas experiências no Brasil. Epidemiol. Serv. Saúde, v.17, n.1, p.59-70, mar. 2008. ria ser analisado periodicamente, a fim de reduzir a mortalidade por causas evitáveis, como os acidentes de trânsito.

Destaca-se, também, que a utilização de eventos georreferenciados na área de saúde, em nível local, tem se tornado cada vez mais útil como ferramenta para planejamento e gestão da área de saúde e, neste sentido, a ocorrência de acidentes de trânsito tem especial apelo para o georreferenciamento, possibilitando uma melhor localização de áreas de risco. Este estudo mostrou que é possível trabalhar com os dados de acidentes de trânsito espacializados, entretanto, o esforço atual que deve ser empregado e tempo necessário para tal são muito grandes. Os bancos de dados existentes necessitam de melhor preenchimento, principalmente no que concerne aos endereços. Como mencionado, uma parte do georreferenciamento ocorreu de forma manual, o que impossibilita atualmente a continuidade desse processo dentro das Secretarias Municipais de Saúde, dado que são poucas aquelas que estão aparelhadas para a produção, manutenção e gerenciamento dos eventos relacionados à saúde. Este trabalho foi testemunha da árdua tarefa que se deve empenhar para conseguir o georreferenciamento de dados de saúde, mesmo restringindo o estudo a um dos tipos de óbitos registrados.

Finalmente, é importante registrar que o planejamento e a execução de políticas públicas serão tão mais eficientes e eficazes quanto mais adequada for a "localização" dos problemas a serem resolvidos. O planejamento e a coleta de informações adequadas e de qualidade e, portanto, a disponibilização de recursos humanos e financeiros para este fim são urgentes quando o que está em jogo é a vida do cidadão.

BARROS, A. J. D.; AMARAL, R. L. et al. Acidentes de trânsito com vítimas: sub-registro, caracterização e letalidade. Cadernos de Saúde Pública, v.19, n.4, p.979-986, jul./ago. 2003. 
CARDOSO, G. O sistema de cadastro, consulta e análise de acidentes de trânsito em Porto Alegre. In: FÓRUM NACIONAL SOBRE SEGURANÇA NO TRÂNSITO, FONAST, 2002.

CARNEIRO, E. O.; SANTOS, R. L. Análise espacial aplicada na determinação de áreas de risco para algumas doenças endêmicas. Revista Sitientibus, Feira de Santana - BA, n. 28, 2003.

CARVALHO, M. S.; CRUZ, O. G. Mortalidade por causas externas: análise exploratória espacial da Região Sudeste do Brasil. In: ENCONTRO NACIONAL DE ESTUDOS POPULACIONAIS, XI. Anais... Caxambu, Abep, 1998.

CARVALHO, M. S.; SANTOS, R. S. Análise de dados espaciais em saúde pública: métodos, problemas e perspectivas. Cadernos de Saúde Pública, Rio de Janeiro, 21(2):361378, mar.-abr. 2005

CARVALHO, S. C.; CÂMARA, G.; CRUZ, O. C.; CORREA, V. Análise de dados de área - análise espacial de dados geográficos. Brasília, 2004, capítulo 5.

IBGE. Malha Digital de Setores Censitários, Situação 2000.

IRTAD - International Road Traffic Accident Database. Selected risk values for the year 2003. Disponível em: <http://www.bast. de/htdocs/fachthemen/irtad/english/we2. html >. Acesso em: 22 abr. 2006.

KILSZTAJN, S.; SILVA, C. R. L. DA; MICHELIN, A. DA C.; FERRAZ, I. L. B. Óbitos por acidentes de trânsito e frota de veículos. In: ENCONTRO NACIONAL DE ESTUDOS POPULACIONAIS, XII. Anais... Caxambu, Abep, v.1, 2000.

MAIA, P.B.; AIDAR, T. Mortes no trânsito urbano: análise segundo local de ocorrência e residência no município de São Paulo entre 2003 e 2005. In: ENCONTRO NACIONAL DE ESTUDOS POPULACIONAIS, XVI. Anais... Caxambu, Abep, 2008.

MELLO JORGE, M. H. P.; LAURENTI, R.; GOTLIEB S. L. D. Análise da qualidade das estatísticas vitais brasileiras: a experiência de implantação do SIM e do SINASC. Ciência \& Saúde Coletiva, 12(3):643-654, 2007.
NERY, M. B.; MONTEIRO, A. M. V. Análise intra-urbana dos homicídios dolosos no Município de São Paulo. In: ENCONTRO NACIONALDE ESTUDOS POPULACIONAIS, XV. Anais... Caxambu, Abep, 2006.

REINHOLD, I. R.; GOLDNER, L. G. O uso de sistemas de informações geográficas na análise de atropelamento de pedestres em áreas urbanas. In: CONGRESSO LATINOAMERICANO DE TRANSPORTE PÚBLICO E URBANO, XIII. Lima (Peru), outubro 2005.

SANTOS, S. M.; NORONHA, P. N. Padrões espaciais de mortalidade e diferenciais sócio-econômicos na cidade do Rio de Janeiro. Cadernos de Saúde Pública, Rio de Janeiro, 17(5):1.099-1.110, set.-out. 2001.

SANTOS, S. M.; BARCELLOS, C.; CARVALHO, M. S.; FLORES, R. Detecção de aglomerados espaciais de óbitos por causas violentas em Porto Alegre, Rio Grande do Sul, Brasil, 1996. Cadernos de Saúde Pública, v.17, n. 5, 2001.

SKABA, D. A.; CARVALHO, M. S.; BARCELLOS, C.; MARTINS, P. C.; TERRON, S. L. Geoprocessamento dos dados da saúde: o tratamento dos endereços. Cadernos de Saúde Pública, Rio de Janeiro, 20(6):17531756, nov.-dez. 2004.

SOUZA, V. R. Mapeamento dos óbitos por local de ocorrência dos acidentes de trânsito na cidade do Rio de Janeiro. Análise espacial dos acidentes de trânsito com vítimas fatais na cidade do Rio de Janeiro em 2003. Dissertação de Mestrado. Rio de Janeiro: Ence/IBGE, 2007.

SOUZA, V. R.; CAVENAGHI, S.; ALVES, J. E. D. Mapeamento dos óbitos por local de ocorrência dos acidentes de trânsito na cidade do Rio de Janeiro. In: ENCONTRO NACIONALDE ESTUDOS POPULACIONAIS, XV. Anais... Caxambu, Abep, 2006.

XIMENES, R. A. DE A. et al. Vigilância de doenças endêmicas em áreas urbanas: a interface entre mapas de setores censitários e indicadores de morbidade. Cadernos de Saúde Pública, Rio de Janeiro, 15(1):53-61, jan.-mar. 1999. 


\section{Resumen}

Análisis espacial de los accidentes de tránsito con víctimas fatales: comparación entre el lugar de residencia y de ocurrencia del accidente en Río de Janeiro

Este trabajo tiene como objetivo comparar la distribución espacial de las muertes por accidentes de tránsito en la ciudad de Río de Janeiro, en 2003, a partir de tres tipos de dirección: residencia de la víctima, lugar de ocurrencia del accidente y lugar de ocurrencia del fallecimiento, a nivel de sector censal. Se utilizó el Estimador de Kernel para verificar si existe o no diferencia en los padrones de áreas de riesgo determinados a partir de los registros de estas direcciones. Se concluyó que existe diferencia en los padrones espaciales, en todos los tipos de dirección utilizados. De esta forma, se muestra como el mapeo de los accidentes, identificando el lugar de ocurrencia de éste, es esencial, pues suministra subsidios a las acciones de políticas públicas para reducción y prevención de los accidentes. Para ello, son necesarias algunas medidas administrativas que permitan la sistematización y el registro de la información adecuada.

Palabras-clave: Accidentes de tránsito. Mortalidad. Análisis espacial. Río de Janeiro.

\section{Abstract \\ Spatial analysis of traffic accidents with fatal victims: comparing place of residence and place of occurrence in Rio de Janeiro}

The purpose of this study is to compare the spatial distribution of deaths by traffic accidents in the City of Rio de Janeiro in 2003, based on three different types of addresses: the victims' residential addresses, address of accident, and that of death, by census track levels. The Kernel Estimation was utilized to estimate risk areas, in order to check for possible differences in the spatial patterns among different ways of classifying addresses. The results show that there are major differences in risk patterns according to address type. Especially, it shows that it is essential to know the place of the accident for clearly pointing out risk areas. This enables authorities to take informed actions in public policies aimed at reducing and preventing traffic accidents. Nonetheless, to enable such analyses in the future, administrative steps should be taken that will allow suitable information to be systematized and organized.

Keywords: Traffic accidents. Mortality. Spatial analysis. Rio de Janeiro.

Recebido para publicação em 05/09/2008. Aceito para publicação em 14/11/2008. 